\title{
Numerical analysis of a reinforced concrete beam under blast loading
}

\author{
Yehya Temsah $^{1}$, Ali Jahami ${ }^{1}$, Jamal Khatib ${ }^{1,2}$, M Sonebi $^{3}$ \\ ${ }^{1}$ Faculty of Engineering, Beirut Arab University, Beirut, Lebanon \\ ${ }^{2}$ Faculty of Science and Engineering, University of Wolverhampton, Wolverhampton, UK \\ ${ }^{3}$ School of Natural and Built Environment, Queens University of Belfast, Belfast, UK
}

Email: j.khatib@bau.edu.lb

\begin{abstract}
The types of Dynamic loads that might face an engineer during any design procedure vary. One of these loads is the explosion's pressure on buildings which is in other words the blast load. This research has examined the possibility of using a finite element method as a tool for predicting the dynamic response of blast loaded reinforced concrete beams. In this study, the advanced software, ABAQUS is used in order to model materials and consider the material nonlinearity, stiffness degradation and strain rate effects. Experimental results for several beams under explosion are chosen to be modeled and verified using ABAQUS. These experiments were carried out at the National University of Defense Technology in China. The results show that the material properties of concrete under impact loads (high strain rates) can be well defined in ABAQUS. Also the built in model CONWEP for blast load in ABAQUS can be used in the simulation process with an acceptable error.
\end{abstract}

\section{Introduction}

Many types of concrete structures may be subjected to blast and shock waves due to different types of blast loading. Some of these explosions are occurring naturally like the lightning phenomenon, and some of them are made by humans such as terrorist attacks. After World War one and two, people started to understand the importance of protecting buildings from blast effect in order to save human lives, and this presented a particular challenge to design. Nowadays this domain became one of most important when designing structures to resist impact loading or explosion in many parts of the world including the Middle East.

An explosion ${ }^{\mathbf{1 , 2}}$ can scientifically be defined as a sudden dissipation of energy which leads to a sudden rise in pressure. This pressure rise forms a wave called a "Blast Wave" that travels starting from a supersonic speed, which decreases as the wave front propagates. The pressure's amplitude has two regions: the positive phase region and the negative phase region as illustrated in Figure 1. Where " $\Delta \mathrm{P}$ " is the over pressure, $" \mathrm{t}^{+}$" is the duration of positive phase and " $\mathrm{t}^{-1}$ is the duration of negative phase. The impulse "I" as known is the area under curve. The positive phase pressure will cause positive impulse density $\left(\mathrm{I}^{+} / \mathrm{A}\right)$ and the negative phase pressure will cause negative impulse density (I/A), where "A" is unit area. Therefore:

$$
\begin{aligned}
& I^{+}=A \int_{i_{a}}^{t_{a+t^{+}+}^{+}}\left(P(t)-P_{o}\right) d t \\
& I^{-}=A \int_{t^{+}++^{-}}^{t_{a+t^{+}+t^{+}}}(P-P(t)) d t
\end{aligned}
$$

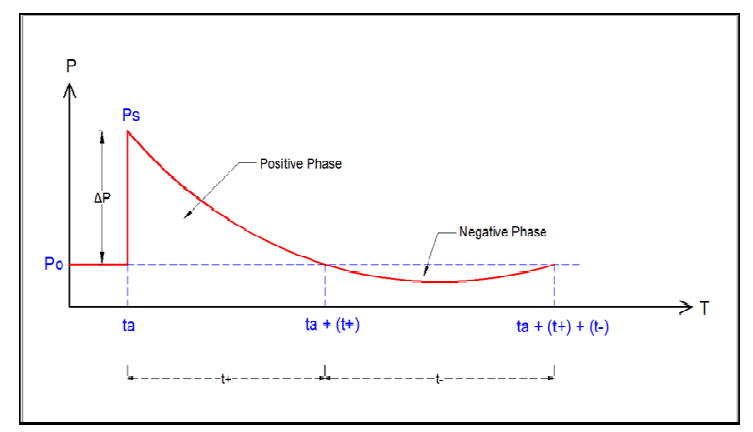

Figure 1. Ideal blast wave behavior (Ardila-Giraldo 2010)

Scaling of the properties of blast waves can be done by Hopkinson-Cranz Scaling ${ }^{3}$. This scaling principle states that when two explosive charges have the same geometry and explosive type but of different size are detonated in the same atmosphere and at equal scaled 
distances, then they will produce the same overpressure stated by:

$$
Z=\frac{R}{Q^{1 / 3}}
$$

Where " $\mathrm{Z}$ " is the scaled distance, $\mathrm{R}$ is the distance from the center of the explosive charge (in meter), and $\mathrm{Q}$ is the equivalent TNT mass $(\mathrm{Kg})$.

As the wave reaches the object, part of it is reflected back and another part is transmitted through the object. The reflection and transmission of waves depend on a mechanical property of objects called the mechanical impedance or (shock impedance of a body) $)^{\mathbf{1}}$. The mechanical impedance $(\mathrm{z})$ is defined as the ratio of pressure change "P'" to the velocity change " $u$ "' at the interface between the two mediums. For concrete structures and since the shock impedance of concrete is much higher than the shock impedance of air, the reflected blast wave from the interface of the two mediums will be magnified and reversible in direction (expansion wave "T"). This will lead into a resultant tension pressure which would cause the spalling of concrete as shown in Figure 2.

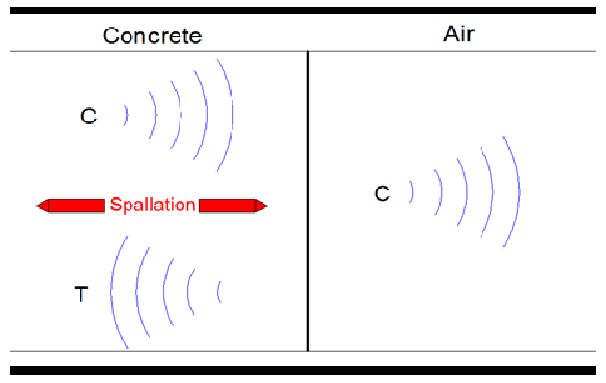

Figure 2. Spalling Phenomenon

The behavior of concrete under high strain loading is different from that under static loading. The strength and stiffness of concrete under dynamic conditions will be higher than under static conditions as illustrated in figure 3. Many researches were conducted to study the tensile and compressive strength of concrete at different strain rates. Some of the published results is presented in Malvar and Crawford (1998) ${ }^{4}$. The behavior of reinforcing steel is also affected by dynamic load conditions. The yield strength will be increased due to strain rate effect as well as the ultimate strength. However, the elastic modulus of steel won't be affected.

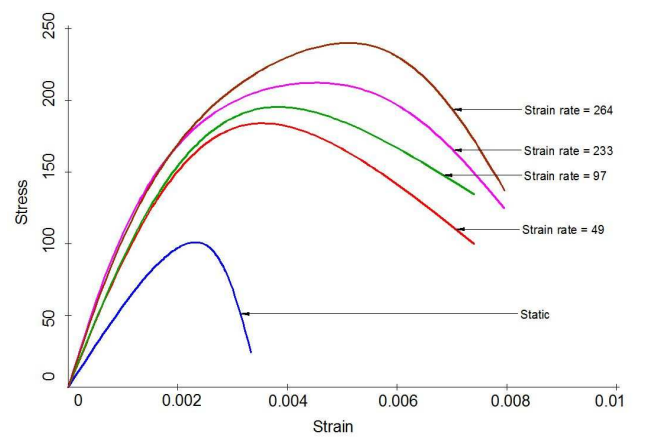

Figure 3. Uniaxial compressive behavior of concrete at different strain rates (Malvar and Crawford 1998)

\section{Aim and Objectives}

The aim of the research was to model the behavior of a Reinforced Concrete Beam under blast loading using ABAQUS. The specific objectives were to:

1- Model the material property under under high strain rate load.

2- Model the blast load using "CONWEP" Built-in model in ABAQUS and check the validity and accuracy of this model.

3- Show the effect of strain rate on the responses of reinforced concrete beams.

\section{Data collection}

The data were collected from the experiment that was carried out by Zhang et $\mathrm{al}^{5}$ National University of Defense Technology. Three different sizes of beams were investigated with dimensional ratios of $3: 4: 5$. The dimensions $(\mathrm{mm})$ were $(850 * 75 * 75),(1100 * 100 * 100)$ and $(1350 * 125 * 125) \mathrm{mm}$. $6 \mathrm{~mm}$ bars were used for the compressive. Tensile and hoop reinforcement. The hoops were placed at $60 \mathrm{~mm}$ centres. Table 1 presents the number and dimensions of beams. The design compressive strength of concrete was $40 \mathrm{MPa}$. The yield stress and ultimate strength of reinforcement steel are 395 $\mathrm{MPa}$ and $501 \mathrm{MPa}$ respectively. The explosive used in this experiment were compressed to a cakey cylinder suspended over the center of the reinforced concrete (RC) beam and detonated electronically. The beam was supported using a steel frame as shown in Figure 4. The mid span displacement of the beam is measured using steel needles which were allowed to move in the vertical direction.
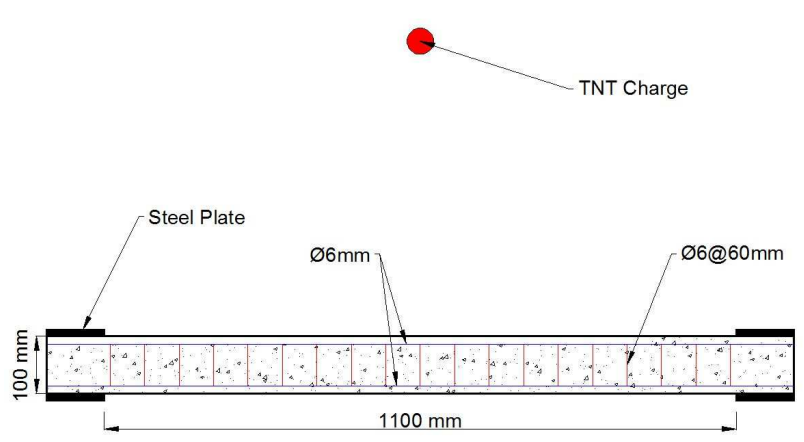

Figure 4. Experimental setup (Zhang et al 2013)

\begin{tabular}{|c|c|c|c|}
\hline Beam & $\begin{array}{c}\text { Dimension } \\
(\mathrm{mm})\end{array}$ & $\begin{array}{c}\text { TNT } \\
(\mathrm{Kg})\end{array}$ & $\begin{array}{c}\text { Standoff distance } \\
(\mathrm{m})\end{array}$ \\
\hline B2-1 & \multirow{2}{*}{$100 \mathrm{X} 100 \mathrm{X} 1100$} & 0.36 & 0.4 \\
\cline { 3 - 4 } & & 0.75 & 0.4 \\
\hline$B 2-2$ & &
\end{tabular}

Table 1. Experimental program (Zhang et al 2013) 


\section{Numerical Modeling}

The volumetric finite element program "ABAQUS" was used to perform nonlinear analysis of the structural element (beam). The model is composed of two main parts: the concrete body that was modeled using a solid element, and steel reinforcement that was modeled as a rebar element. A Dynamic explicit analysis step was chosen for the case with a reasonable time step close to the experimental interaction time.

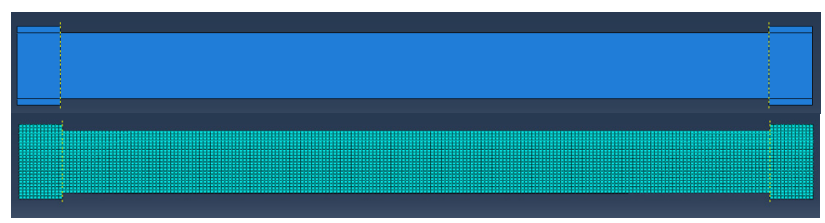

Figure 5. Finite Element Modeling of beam

The Concrete Damage Plasticity Model ${ }^{6}$ will be used to define the behavior of concrete. This model works with static and dynamic load conditions. It was derived by Lubliner ${ }^{7}$ in 1989 and developed by Lee and Fenves ${ }^{8}$ in in 1998. It represents the nonlinear behavior of concrete using different input parameters such as: inelastic strain, cracking strain, stiffness degradation and recovery, and other parameters.

The behavior of concrete in compression and tension according to CDP method in ABAQUS is illustrated in Figures 6 and 7 respectively. If the load on the concrete specimens is released during the softening stage, the elastic stiffness is reduced and this can range from zero (undamaged) to one (total damage).

As for reinforcing steel, they can be modeled using several methods. For this simulation we will consider the elasto-plastic behavior of reinforcing steel, and we will assume a perfect bond between concrete and steel which is not accurate; since there is some slipping between the two materials (concrete and steel). But for now we are not interesting in the interaction between these materials.

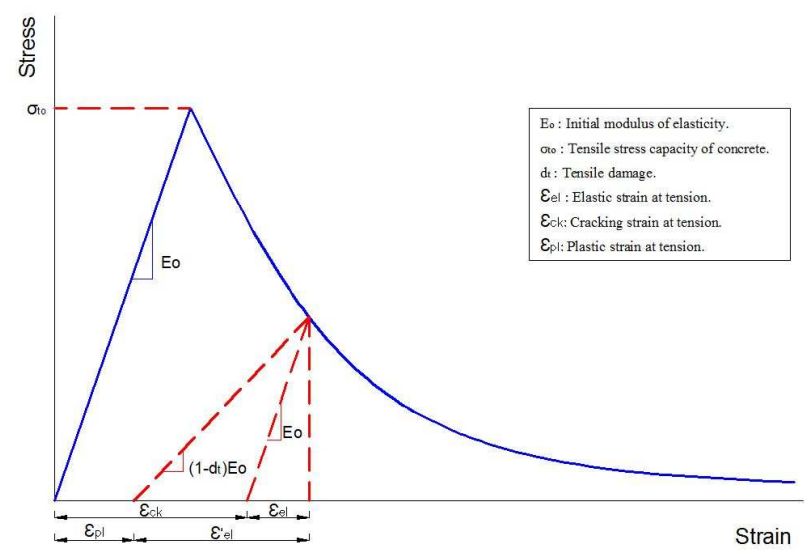

Figure 6. Uniaxial behavior of concrete under tension

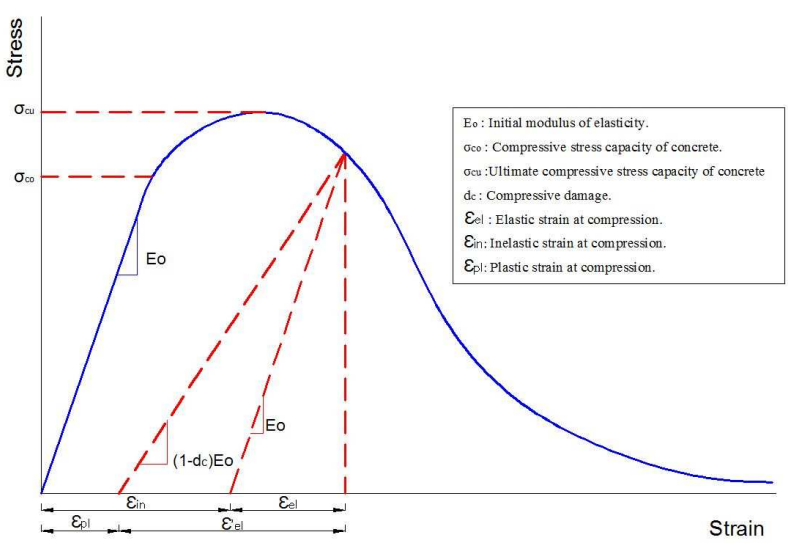

Figure 7. Uniaxial behavior of concrete under compression (Hibbitt et al 2011)

In this work, the built-in CONWEP model was used to define the blast load. The model provides the values of maximum overpressure, arrival time, positive phase duration and the exponential decay coefficient. Using the above parameters, the variation of incident pressure and reflected pressure can be constructed (Figure 1).

\section{Model calibration}

The model was calibrated until reaching an acceptable error. Two verifications were done for this process: comparing mid-span displacements and damage zone length. Table 2 and Figure 8 show the Mid-Span displacements for Beams B2-1 to B2-2. As shown the difference between experimental and numerical analysis in small. Therefore the first verification is acceptable.

\begin{tabular}{|c|c|c|c|}
\hline \multirow{2}{*}{$\begin{array}{c}\text { Beam } \\
\text { Sample }\end{array}$} & \multicolumn{2}{|c|}{ Mid-Span Displacement (mm) } & \multirow{2}{*}{$\begin{array}{c}\text { Absolute } \\
\text { error } \%\end{array}$} \\
\cline { 2 - 3 } & Experimental & Numerical & 6 \\
\hline$B 2-1$ & 25 & 23.5 & 6.25 \\
\hline$B 2-2$ & 40 & 36.3 & 9.3 \\
\hline
\end{tabular}

Table 2. Mid-Span Displacement for B2 samples

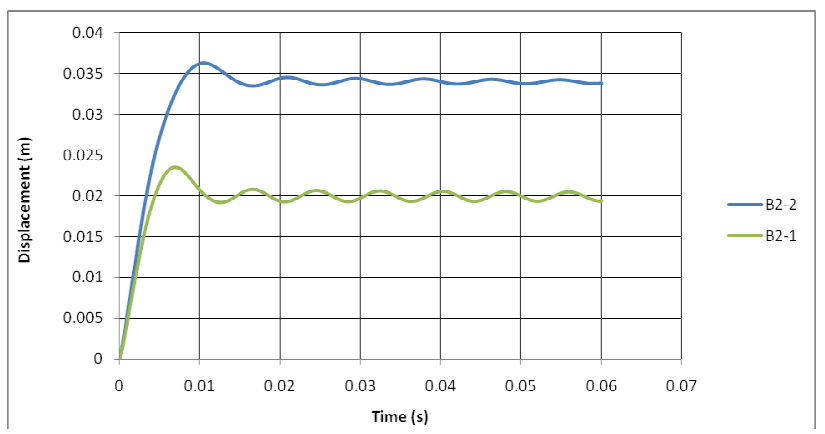

Figure 8. Time-Displacement Curves

As for the damage pattern, Tables 3 and 4 show the compression fracture zone width and the tensile fracture zone width (spalling area) in both Experimental work and Numerical analysis. Also Figures 9 and 10 presents graphically the damage pattern in both compression and 
tension zones for beams B2-1 and B2-2 respectively. According to these data the second verification is achieved, and as a final conclusion the experiment is verified and the model therefore is ready for further studies.

\begin{tabular}{|c|c|c|}
\hline \multirow{2}{*}{$\begin{array}{c}\text { Beam } \\
\text { Sample }\end{array}$} & \multicolumn{2}{|c|}{ Compression Fracture Zone Width $(\mathrm{cm})$} \\
\cline { 2 - 3 } & Experimental & Numerical \\
\hline$B 2-1$ & 8 & 6 \\
\hline$B 2-2$ & 12 & 10.25 \\
\hline
\end{tabular}

Table 3. Compression Fracture Zone width

\begin{tabular}{|c|c|c|}
\hline \multirow{2}{*}{ Beam } & \multicolumn{2}{|c|}{ Tensile Fracture Zone width $(\mathrm{cm})$} \\
\cline { 2 - 3 } Sample & Experimental & Numerical \\
\hline$B 2-1$ & 7 & 5.9 \\
\hline$B 2-2$ & 15 & 13.75 \\
\hline
\end{tabular}

Table 4. Tensile Fracture Zone width

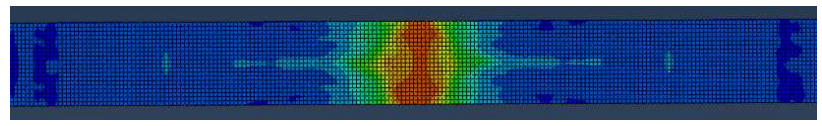

(a)

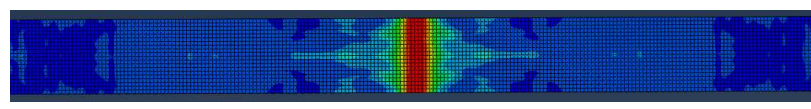

(b)

Figure 9. B2-1 zone damage.

a) Compression damage $\quad$ b) Tensile damage

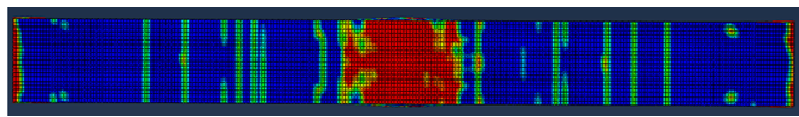

(a)

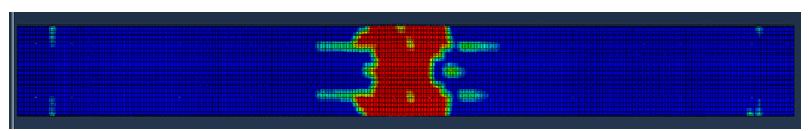

(b)

Figure 10. B2-2 zone damage.
a) Compression damage
b) Tensile damage

\section{Further Study}

After Calibration process, the Effect of strain rate on structural response was studied. First the effect of strain rate on Mid-Span displacement is presented in Figures 11 to 12 as the following:

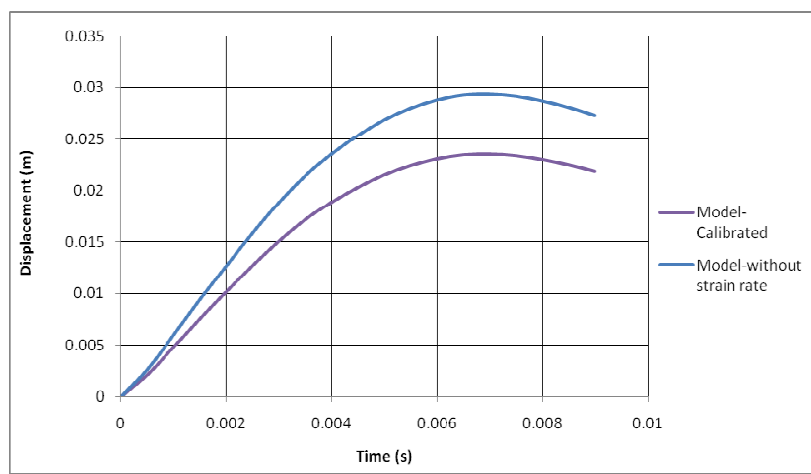

Figure 11. Strain rate effect on beam B2-1

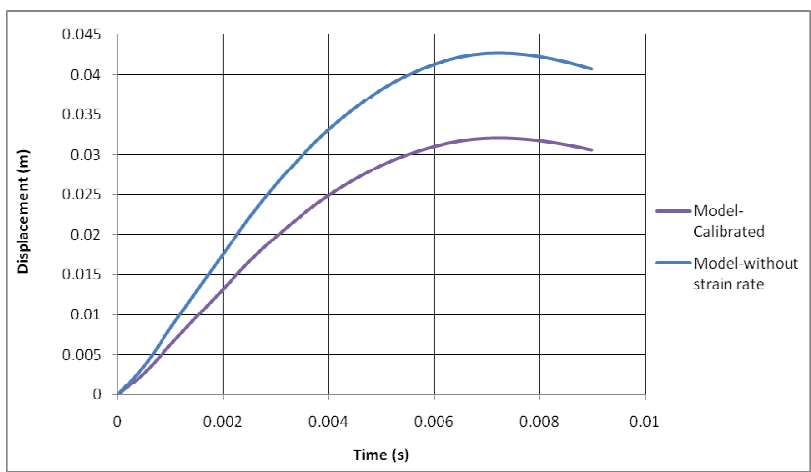

Figure 12. Strain rate effect on beam B2-2

In addition, the effect of strain rate on support reaction force is illustrated in Figures 13 and 14:

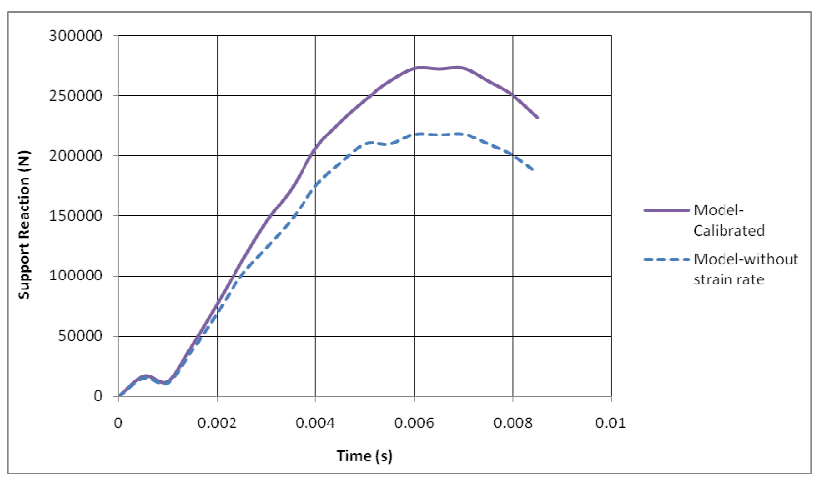

Figure 13. Strain rate effect on beam B2-1

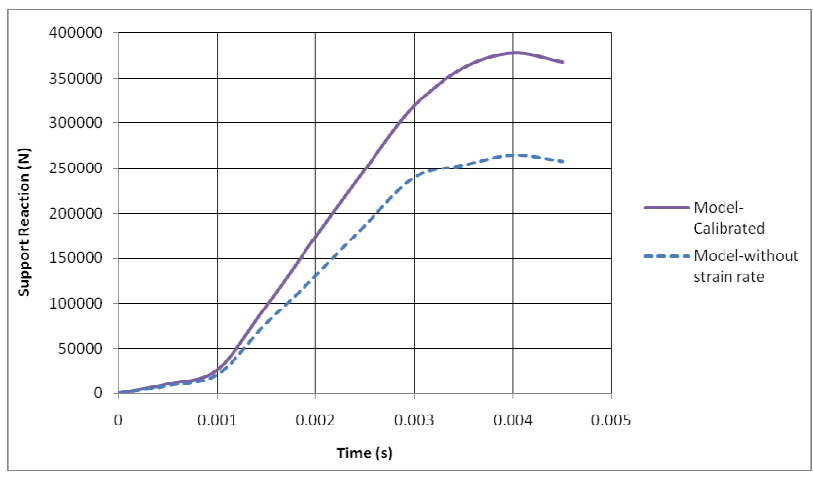

Figure 14. Strain rate effect on beam B2-2 
All previous figures proved that the beam has a softer behavior in the absence of strain rate effects.

\section{Conclusion}

The following conclusions can be drawn from the current investigation:

1- The prediction of the the response of blast loaded reinforced concrete beams using a finite element program such as ABAQUS is possible.

2- The concrete properties must be defined using a nonlinear model (CDP). As for steel reinforcement it must be defined considering the elasto-plastic behavior.

3- The strain rate has a great effect on beam response which makes it important to be considered.

4- The Built-in CONWEP model successfully simulates the real explosion wave in the case of single structural elements without reflection phenomenon.

\section{Further research}

Further research may include the following:

1- Modeling the interaction between concrete and reinforcing steel and its effects on the crack pattern.

2- Modeling the effect of reflection and transmission of blast waves on the damage pattern of RC elements.

3- Modeling the thermal effect of an explosion on RC elements.

\section{References}

1. K. Ramamurthi, 2014, An Introduction to Explosions and Explosion Safety, Department of Mechanical Engineering,IIT Madras, from: http://nptel.ac.in/

2. Ardila-Giraldo, O. A., 2010. Investigation on the Initial Response of Beams to Blast and Fluid Impact, PhD thesis, Purdue University.

3. Magnusson, J., 2007. Structural Concrete Elements subjected to Air Blast Loading, Licentiate thesis, Royal Institute of Technology, Division of Concrete Structures, Stockholm, Sweden.

4. Malvar, L.J., Crawford, J.E., 1998. Dynamic increase factors for concrete, Department of Defense Explosives Safety Seminar (DDESB), Orlando FL, USA.

5. Duo Zhang, ShuJian Yao, Fangyun Lu, XuGuang Chen, Guhui Lin, Wei Wang \& Yuliang Lin. (July 5, 2013). Experimental study on scaling of RC beams under close-in blast loading. Retrieved December 7 ,
2015 from: http: // www.sciencedirect.com /science/ article/pii/ S1350630713002203.

6. Hibbitt, Karlsson, Sorensen, 2011, ABAQUS User's Manual, Pawtucket, 6th Edition.

7. Lublinear, J., Oliver, J., Oller, S., Onate, E., 1989. A plastic-damage model for concrete, Solids and Structures, Vol. 25, No. 3, pp. 299-326.

8. Lee, J., Fenves, G., 1998. Plastic-damage model for cyclic loading of concrete structure, Engineering Mechanics, Vol. 124, No. 8, pp. 892-900. 